\section{SHEA/DC Training Course -- Successful Pilot Run}

The first SHEA/CDC joint training course in hospital epidemiology was held at the Centers for Disease Control in Atlanta, Georgia, August 11-13, 1988. Attendance was limited to 20 participants, the majority of whom were current (or recent) infectious disease fellows; many attended because they had been, or were soon to be named, hospital epidemiologists.

The course highlight was the series of three "hands-on" problems. The first was designed to show the importance of moving from "high-tech crisis intervention" medicine into the organized "Iong division" method of hospital epidemiology. The second problem led the group through a very complicated investigation of excess mortality in a neonatal unit. The third showed the broadened scope of hospital epidemiology with an exercise involving a noninfectious "outbreak" in the hospital setting.

Additional didactic sessions (1) described the scope of hospital epidemiology, the variety of surveillance systems applicable to hospital work, ways in which computerization can be helpful in surveillance, concepts of epidemic and endemic problems in hospitals, and "noninfection" hospital epidemiology; (2) reviewed important governmental and other regulatory agencies; (3) discussed the impact of AIDS on the hospital epidemiologist; and (4) dealt with the important, very practical details of finding and designing a position as a hospital epi- demiologist.

The course clearly addressed an important training need and also allowed "new" hospital epidemiologists to establish contact with colleagues and resource personnel at SHEA and CDC. Course faculty included Drs. R. Aber, G. Counts, M. Decker, N.J. Ehrenkranz, M. Favero, W. Hierholzer, W. Jarvis, A. Kaiser, W. Martone, and J. McGowan; and Ms. J. Garner.

Because of the enthusiasm of the attendees and the lively response to the initial advertisements for the course (over 50 applicants for the 20 "first-come, first-served" spots), plans are being made to establish an annual training course. The next course is scheduled for April 1989 and the SHEA leadership is discussing mechanisms to secure training grants to offset some of the travel costs for participants.

Allen B. Kaiser, MD Nashville. Tennessee

\section{Baltimore in ' 89 !}

Baltimore? March? It will be outstanding! SHEA and ICEHE are cosponsoring a conference entitled, "Hospital Epidemiology: New Challenges and Controversies." It is SHEA's first venture into the national meeting scene and should be a terrific offering. The presenters and discussants include many of our members and well-known experts on topics to be discussed (not necessarily mutually exclusive). However, in order for us to have a successful meeting, we need vour help. We need you to come, attend the sessions, and join the discussions; you may consider presenting a poster if you want to participate more actively. An abstract form for the poster session appears on p. 486 of the journal. For additional registration information, please write to: Hospital Epidemiology: New Challenges and Controversies, 6900 Grove Road, Thorofare, New Jersey 08086-9447.

\section{Reader Inquiry}

I would be interested in hearing from any readers who work in state institutions for the developmentally disabled (mentally, retarded), in regard to setting up infection control standards, programs, policies, etc. Most guidelines for infection control are geared to the hospital setting. but a lot of adapting must be done for other institutions, because of the uniqueness of our clientele.

Thank you.

\section{Marney Deloy, RN-AD Nursing Nursing Services Coordinator Infection Control Nurse \\ Redfield State Hospital and School Redfield, South Dakota 57469}

Brief items of interest for the SHEA Neastetter mathe sent to Roberl A. Woinstein, MD, SHEA Nerusteler Editor. Division of Infections Diseases, Michael Reese Hospital. Lake Shore Driver at 31st St., Chicago, IL 60616. Coppy must be typed, double-spaced, and may not exreed fiue pages. 